\title{
Preparation of oxime oxalate amides and their use in free-radical mediated syntheses of lactams
}

\author{
Eoin M. Scanlan and John C. Walton* \\ University of St. Andrews, School of Chemistry, St. Andrews, Fife, UK KY16 9ST. E-mail: jcw@st-and.ac.uk; \\ Fax: 01334 463808; Tel: 01334463864
}

Received (in Cambridge, UK) 21st June 2002, Accepted 18th July 2002

First published as an Advance Article on the web 16th August 2002

Photosensitised decomposition of oxime oxalate amides is a useful new route to carbamoyl radicals that may cyclise to afford $\beta$ - or $\gamma$-lactams.

Mild 'clean' free radical precursors, as alternatives to organotin hydrides, for large and small scale organic syntheses are very desirable. Other group 14 element hydrides, xanthates, hypophosphorous acid derivatives and cyclohexadienyl derivatives are prominent among the new alternatives. ${ }^{1,2}$ It was known ${ }^{3,4}$ that $\mathrm{C}$-centred radicals $\mathrm{R} \cdot$ could be obtained by photolyses of oxime esters $\mathrm{R}^{1} \mathrm{R}^{2} \mathrm{C}=\mathrm{NOC}(\mathrm{O}) \mathrm{R}$. Furthermore, suitably unsaturated radicals generated in this way cyclised in yields of over $70 \% .^{5}$ By analogy, the structural features of oxime oxalate amides 3 hinted that they might function as novel, clean sources of aminoacyl radicals (carbamoyl radicals) 4. Suitably unsaturated aminoacyl radicals could then ring close, so that the final outcome would be the establishment of a new synthetic route from secondary amines to lactams.

The only previous synthesis of an oxalate of type $\mathbf{3}$ utilised acetone $O$-(chlorooxalyl)oxime $\left(2 \mathrm{R}^{1}=\mathrm{R}^{2}=\mathrm{Me}\right)$ together with 2 equiv. of aniline to afford the corresponding amide. ${ }^{6}$ However, we found that this method failed for most other amines. Attempts to make mono-amides of oxalyl chloride and condense these with oximes also failed. However, when $\mathbf{2}$ was treated with 1 equiv. of a primary or secondary amine, in the presence of 1 equiv. of pyridine at $0{ }^{\circ} \mathrm{C}$ good yields of the corresponding oxime oxalate amides were obtained (Scheme 1).

Solutions of individual oxime oxalate amides in tertbutylbenzene ( $c a .0 .05 \mathrm{~mol} \mathrm{dm}^{-3}$ ) were deaerated and photolysed with UV light from a $500 \mathrm{~W} \mathrm{Hg}$ arc in the resonant cavity of a $9 \mathrm{GHz}$ EPR spectrometer. For all of $\mathbf{3 a}-\mathbf{g}$ spectra were

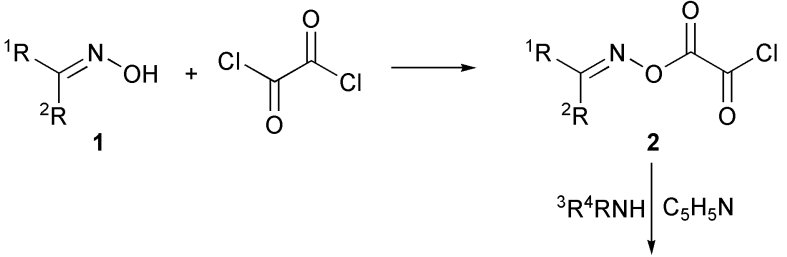

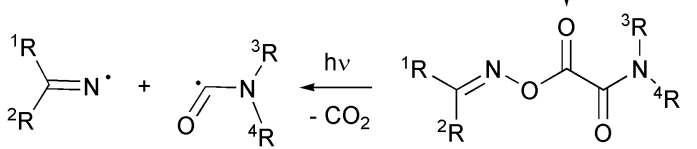

$$
\begin{aligned}
& 543 \\
& \mathrm{Bn}=\mathrm{PhCH}_{2} \quad{ }^{1} \mathrm{R} \quad{ }^{2} \mathrm{R} \quad{ }^{3} \mathrm{R} \quad{ }^{4} \mathrm{R} \quad \text { Yield } 3 \% \\
& \text { a } \mathrm{Me} \mathrm{Me} \mathrm{Ph} \mathrm{H} 65 \\
& \text { b } \mathrm{Me} \mathrm{Me} \mathrm{Bn} \mathrm{H} \quad 67 \\
& \text { c } \mathrm{Me} \mathrm{Me} \mathrm{Bn} n \text {-Bu } 54 \\
& \text { d } \mathrm{Ph} \quad \mathrm{H} \quad \mathrm{Bn} \text { allyl } 44 \\
& \text { e } \mathrm{Ph} \mathrm{H} \quad \mathrm{Bn} \longrightarrow 95 \\
& \text { f } \mathrm{Ph} \mathrm{H} \quad \mathrm{Bn} / \mathrm{Ph} 85 \\
& \text { g } \mathrm{Ph} \mathrm{H} \mathrm{Bn} 70
\end{aligned}
$$

Scheme 1 Synthesis and photodissociation of oxime oxalate amides. observed in the temperature range $200-320 \mathrm{~K}$. Considerable enhancement of signal intensity was achieved on addition of 1 or more equiv. of 4-methoxyacetophenone (MAP) as a photosensitiser. Fig. 1 shows the remarkable spectrum obtained on MAP sensitised photolysis of $\mathbf{3 g}$. A clear 'snapshot' of all three radicals was captured, that proved their intermediacy, and enabled them to be characterised.

The two groups of three lines at the left and right ends of the spectrum (marked I in Fig. 1) are due to the iminyl radical $\mathrm{PhC}(\mathrm{H})=\mathrm{N} \cdot$. The well-spaced $\mathrm{N}$-triplet (marked A) is due to the aminoacyl radical $\mathbf{4 g}$. This latter radical contains a vinyl group suitably placed for a 5-exo-trig $\left[\mathbf{C}^{5 \mathbf{x}}\right]^{7}$ cyclisation and indeed the doublet of triplets (marked $\mathrm{C}$ ) is due to the cyclised 2-oxopyrrolidinylmethyl radical $\mathbf{7 g}(n=2){ }^{8}$ The spectra from most of the other oxime oxalate amides showed iminyl 5 and aminoacyl radicals 6. In no case was an iminoxyl radical ${ }^{1} \mathrm{R}^{2} \mathrm{RC}=\mathrm{NO} \cdot$ observed. The EPR spectra demonstrated, therefore, that scission of the $\mathrm{N}-\mathrm{O}$ bonds of $\mathbf{3}$ occurred cleanly and that this was followed by rapid $\mathrm{CO}_{2}$ loss to afford radicals 4 that could subsequently cyclise.

The best conditions for preparations of lactams (9-11) were established by means of a series of photolyses with compound 3g. Dilute solutions in toluene, with a three-fold excess of MAP, were found to afford $\mathrm{N}$-benzyl-3-methylpyrrolidin-2-one $(\mathbf{9 g})$ in $>80 \%$ yield. ${ }^{9} \mathrm{GC}-\mathrm{MS}$ analysis showed that the $N$-formyl byproduct $(\mathbf{8 g})$ was negligible $(<1 \%)$. It was expected that $\beta$ lactam formation would be more difficult because this would involve disfavoured 4-exo-ring closures $\left[\mathbf{C}^{\mathbf{4}}\right]$. Although the $40 \%$ yield of $\mathrm{N}$-benzyl-3-methylazetidin-2-one (9d) was certainly modest, it compared favourably with previous radical routes to azetidin-2-ones involving aminoacyl radicals generated from Co-salophens ${ }^{10}$ or amidocyclohexadienes. ${ }^{11}$

Ring closures of the aminoacyl radicals $(\mathbf{4 e}, \mathbf{4 f})$ derived from the cyclohexenyl- and phenyl-substituted materials $\mathbf{3 e}$ and $\mathbf{3 f}$ afforded the bicyclic $\beta$-lactam 10 and 3-benzyl-substituted $\beta$ lactam 11 respectively. In both cases the cyclised radicals were more stabilised (one was secondary and the other secondarybenzylic) and this favoured 4-exo-ring closure. Yields of $\mathbf{1 0}$ and 11 were good and compared very favourably with those of $\beta$ -

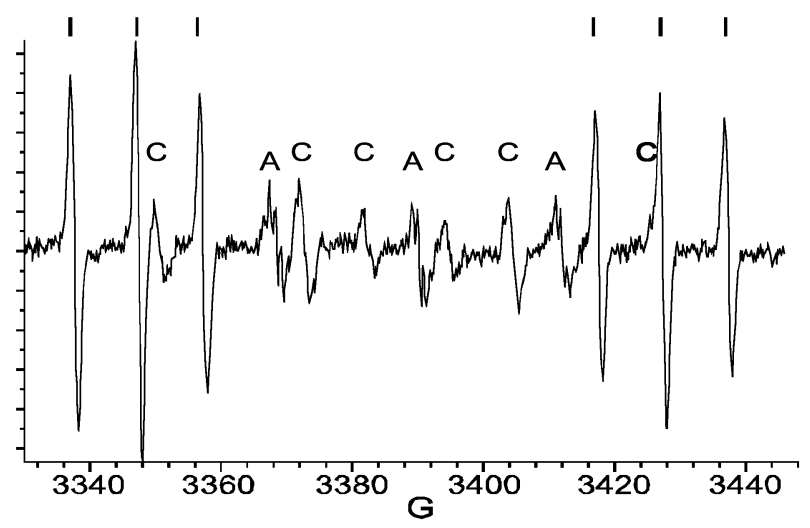

Fig. 19.4 GHz EPR spectrum obtained on photolysis of a solution of $\mathbf{3 g}$ and MAP in tert-butylbenzene at $220 \mathrm{~K}$. I; iminyl $5 \mathbf{g}$, A; aminoacyl 4g, C; $N$ benzyl-2-oxopyrrolidinylmethyl radical $\mathbf{7 g}$. 
lactams prepared by organotin hydride mediated cyclisations of 1-amidoalkyl radicals. ${ }^{12-14}$

An interesting feature was that both $\mathbf{1 0}$ and $\mathbf{1 1}$ were obtained as hydroxyl derivatives, the former as a 5:1 mixture of anti- and $s y n$-isomers ${ }^{15}$ and the latter as a pair of diastereoisomers $(3: 1)$ (Scheme 2). Probably hydrogen abstraction from the toluene solvent was slower for the secondary precursor radical for $\mathbf{1 0}$ and the benzylic precursor radical for 11, so that addition of dissolved dioxygen supervened. The peroxyl radicals formed in this way would be converted to more reactive oxyl radicals (by self-coupling and $\mathrm{O}_{2}$ loss) ${ }^{16}$ that did abstract hydrogen, hence affording the hydroxyl derivatives.

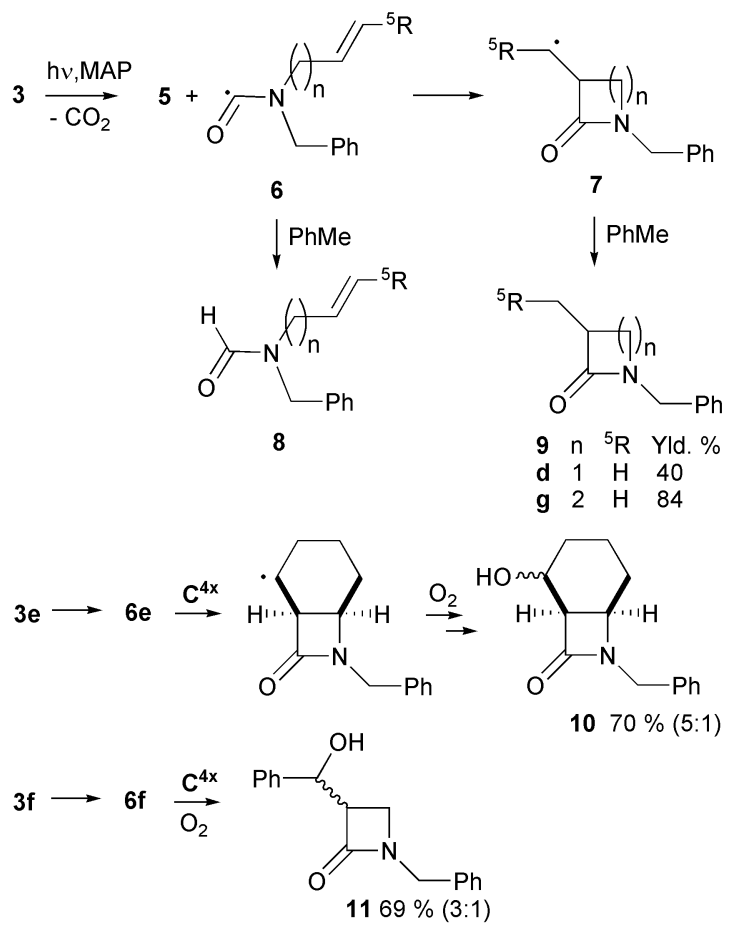

Scheme 2 Preparation of $\beta$ - and $\gamma$-lactams via photosensitised reactions of oxime oxalate amides.

Iminyl radicals $\mathbf{5}$ are inevitably formed as co-intermediates with the desired aminoacyls 4 . However, the only significant product derived in each case from $\mathbf{5}(\mathbf{d}-\mathbf{g})$ was benzaldehyde. Evidently $\mathbf{5}$ abstracts hydrogen from the solvent to give $\mathrm{PhC}(\mathrm{H})=\mathrm{NH}$ that is hydrolysed on work-up. Under the experimental conditions described above, hydrogen abstraction prior to cyclisation was unimportant and negligible amounts of formamides $\mathbf{8}$ were produced. In practice, therefore, interference from undesired by-products was unproblematic.

We conclude that photosensitised decompositions of oxime amide oxalates provide an efficient and general route to aminoacyl radicals. Good yields of $\gamma$-lactams can be obtained from ring closures of 4-unsaturated aminoacyl radicals. Similarly, $\beta$-lactams can be obtained from secondary amines with alk-2-enyl substituents, and related amines, in a two-step process. If the unsaturated bond is functionalised with an aryl or alkyl group at the 3-position in the amine, the cyclised azetidinylalkyl radical is stabilised and consequently a hydroxybenzyl or hydroxyalkyl side chain is introduced with potential for additional functional group manipulation.

We thank the EPSRC for financial support (Grant GR/ N37674/01)

\section{Notes and references}

1 P. A. Baguley and J. C. Walton, Angew. Chem., Int. Ed., 1998, 37, 3072 .

2 A. Studer and S. Amrein, Synthesis, 2002, 835.

3 M. Hasebe, K. Kogawa and T. Tsuchiya, Tetrahedron Lett., 1984, 25, 3887; M. Hasebe and T. Tsuchiya, Tetrahedron Lett., 1986, 27, 3239.

4 M. Hasebe and T. Tsuchiya, Tetrahedron Lett., 1987, 28, 6207; M. Hasebe and T. Tsuchiya, Tetrahedron Lett., 1988, 29, 6287.

5 A. J. McCarroll and J. C. Walton, J. Chem. Soc., Perkin Trans. 2, 2000, 2399.

6 J. C. Jochims, S. Hehl and S. Herzberger, Synthesis, 1990, 12, 1128

7 A. J. McCarroll and J. C. Walton, Angew. Chem., Int. Ed., 2001, 40, 2225; A. J. McCarroll and J. C. Walton, J. Chem. Soc., Perkin Trans. 1, 2001, 3215.

8 EPR parameters for the radicals derived from $\mathbf{3 g}$ in tert-butylbenzene at $220 \mathrm{~K}$ were: iminyl (I) $g=2.0034, a(\mathrm{~N})=9.9, a(\mathrm{H})=79.9 \mathrm{G}$; aminoacyl $(\mathrm{A}) g=2.0017, a(\mathrm{~N})=21.7 \mathrm{G}$; cyclised radical $7 \mathrm{~g}(\mathrm{C}) \mathrm{g}=$ $2.0025, a(2 \mathrm{H})=22.3, a(1 \mathrm{H})=31.6 \mathrm{G}(1 \mathrm{G}=10 \mathrm{mT})$.

9 A solution of oxime oxalate amide $3 \mathbf{g}(0.8 \mathrm{~g}, 2.38 \mathrm{mmol})$, and MAP (1.0 $\mathrm{g}, 7.14 \mathrm{mmol})$ in toluene $400 \mathrm{~cm}^{3}$ was heated to $100{ }^{\circ} \mathrm{C}$ and photolysed with a $400 \mathrm{~W}$ UV lamp in a quartz cold finger immersed in the solution for $5 \mathrm{~h}$. The mixture was allowed to cool to room temperature and then evaporated to dryness to give the crude lactam. Column chromatography (DCM: $1.0 \% \mathrm{MeOH}$ ) gave the pure cyclised product, 1-benzyl3 -methyl-pyrrolidin-2-one $(\mathbf{9 g})$ as a colourless oil $(378 \mathrm{mg} ; 84 \%) ; \delta_{\mathrm{H}}$ $\left(300 \mathrm{MHz}, \mathrm{CDCl}_{3}\right) 1.25\left(3 \mathrm{H}, d, J=7.2 \mathrm{~Hz}, \mathrm{CH}_{3}\right), 1.60(1 \mathrm{H}, \mathrm{m}, \mathrm{CH})$ $2.25(1 \mathrm{H}, \mathrm{m}, \mathrm{CH}), 2.52(1 \mathrm{H}, \mathrm{m}, J=7.2 \mathrm{~Hz}), 3.19\left(2 \mathrm{H}, \mathrm{m}, \mathrm{CH}_{2}\right) 3.19$ $\left(2 \mathrm{H}, \mathrm{m}, \mathrm{CH}_{2}\right), 4.42(1 \mathrm{H}, \mathrm{AB}, \mathrm{CH}), 4.48(1 \mathrm{H}, \mathrm{AB}, \mathrm{CH}), 7.21-7.37(5$ $\mathrm{H}, \mathrm{m}, \mathrm{ArH}) ; \delta_{\mathrm{C}}\left(75 \mathrm{MHz}, \mathrm{CDCl}_{3}\right) 16.4\left(\mathrm{CH}_{3}\right), 27.1\left(\mathrm{CH}_{2}\right), 36.8(\mathrm{CH})$, $44.7\left(\mathrm{CH}_{2}\right), 46.8\left(\mathrm{CH}_{2}\right), 127.5,128.1,128.6(5 \times \mathrm{CH}), 136.7(\mathrm{C}), 177.4$ $(\mathrm{C}=\mathrm{O}) ; \mathrm{m} / \mathrm{z}$ (relative intensity) $189\left(100, \mathrm{M}^{+}\right), 174(11), 161$ (12), 91 (90); found $\mathrm{M}^{+} 189.1153, \mathrm{C}_{12} \mathrm{H}_{15} \mathrm{NO}$ requires 189.1154

10 G. B. Gill, G. Pattenden and S. J. Reynolds, J. Chem. Soc., Perkin Trans. 1, 1994, 369; G. Pattenden and S. J. Reynolds, ibid., 1994, 379.

11 L. V. Jackson and J. C. Walton, Chem. Commun., 2000, 2327.

12 H. Ishibashi, C. Kameoka, H. Iriyama, K. Kodama, T. Sato and M. Ikeda, J. Org. Chem., 1995, 60, 1276.

13 H. Ishibashi, C. Kameoka, K. Kodama, T. Sato and M. Ikeda, Tetrahedron, 1996, 52, 489.

14 A. J. Clark and J. L. Peacock, Tetrahedron Lett., 1998, 39, 1265.

15 Note that this compound (stereochemistry undefined) was previously obtained, as a mixture with the 6- and 7-hydroxylated analogues, by biohydroxylation of the parent azabicycle with Beauveria sulfurescens: A. Archelas, J. D. Fourneron and J. D. Furstoss, Tetrahedron Lett., 1988, 29, 6611

16 J. A. Howard, in Free Radicals, ed. J. K. Kochi, Wiley, New York, 1973, vol. II, ch. 12 , p. 3 